\title{
Spectrophotometric Determination of Low Levels of the Orthophosphate Anion as Molybdenum Blue using Sodium Thiosulphate Reducing agent
}

\author{
IRENE NALUMANSI ${ }^{1 *}$, GRACE BIRUNGI ${ }^{1}$, BRENDA MOODLEY ${ }^{2}$ \\ and EMMANUEL TEBANDEKE ${ }^{3}$
}

'Department of Chemistry, Mbarara University of Science and Technology, Uganda.

${ }^{2}$ School of Chemistry and Physics, University of Kwa Zulu-Natal, Westville Campus, South Africa.

${ }^{3}$ Department of Chemistry, Makerere University, Uganda.

*Corresponding author E-mail: inalumansi@ must.ac.ug

http://dx.doi.org/10.13005/ojc/360608

(Received: November 10, 2020; Accepted: December 11, 2020)

\section{ABSTRACT}

A simple spectrophotometric method for the determination of low levels of the orthophosphate $\left(\mathrm{PO}_{4}{ }^{3-}\right)$ in environmental water systems is reported. The method is based the formation of the phosphomolybdate from the condensation of molybdate and orthophosphate in aqueous acid medium followed by reduction with sodium thiosulphate to form phosphomolybdenum blue. The system obeys Beer's law at $880 \mathrm{~nm}\left(\lambda_{\max }\right)$ in the $0.005-0.06 \mathrm{mg} \mathrm{P} \mathrm{mL}^{-1}$ phosphate concentration range. Molar absorptivity, Sandell's sensitivity and correlation coefficient values for the determination were $57526 \mathrm{~L} \mathrm{~mol}^{-1} \mathrm{~cm}^{-1}, 0.2835$ $\mu \mathrm{g} \mathrm{cm}^{-2}$ and 0.9948 respectively. The limit of detection was $2.213 \times 10^{-3} \mathrm{mg} \mathrm{P} \mathrm{mL}^{-1}$. The results of $\mathrm{PO}_{4}{ }^{3-}$ determination in water samples obtained using the spectrophotometric method developed in this study, compare favourably with those generated using the Murphy and Riley method which is commonly used for this analysis. Therefore, the study ably demonstrates the suitability of the present spectrophotometric method for analysis of the orthophosphate in environmental water samples.

Keywords: Spectrophotometric, Phosphomolybdate, Molybdenum blue,

Orthophosphate anion, Sodium thiosulphate

\section{INTRODUCTION}

Phosphorus $(\mathrm{P})$ a vital nutrient to human, animal and plant growth occurs naturally in rocks and soils as phosphorite or hydroxyapatite, $\mathrm{Ca}_{3}\left(\mathrm{PO}_{4}\right)_{2}$. $\mathrm{Ca}(\mathrm{OH})_{2}$, apatite, $\mathrm{Ca}_{3}\left(\mathrm{PO}_{4}\right)_{2} \cdot \mathrm{CaF}_{2}$, vivianite, $\mathrm{Fe}_{3}\left(\mathrm{PO}_{4}\right)_{2} \cdot 8 \mathrm{H}_{2} \mathrm{O}$ and aluminium phosphate 1 . Since $\mathrm{P}$ serves as a nutrient in the food chain, supplementing the native $P$ in the soil and animals' diet where it is lacking may be a necessity. This can result in excess $\mathrm{P}$ moving from agricultural areas especially where animal wastes are being used as fertilisers to other environmental systems ${ }^{2}$. These phosphates stimulate the growth of phytoplankton and aquatic plants which provide food for many organisms including zooplanktons, fish, humans and other mammals. This may result in eutrophication of waters and its related effects of anoxic conditions ${ }^{3,4,5}$; which leads to

This is an Open Access article licensed under a Creative Commons license: Attribution 4.0 International (CC- BY). Published by Oriental Scientific Publishing Company @ 2018 
deterioration in water quality and depletion of aquatic species. Phosphorus in freshwaters ranges from 0.005 to $0.02 \mathrm{mg} \mathrm{L}^{-1} \mathrm{PO}_{4}-\mathrm{P}$ in most natural surface waters, $0.001 \mathrm{mg} \mathrm{L}^{-1} \mathrm{PO}_{4}-\mathrm{P}$ in some pristine waters and as high as $200 \mathrm{mg} \mathrm{L}^{-1} \mathrm{PO}_{4}-\mathrm{P}$ in some enclosed saline waters. Average groundwater levels are about $0.02 \mathrm{mg} \mathrm{L}^{-1} \mathrm{PO}_{4}-\mathrm{P}^{6,7}$. Due to a few absorbing surfaces and constant mixing in water bodies, low $\mathrm{P}$ levels are responsible for increasing biological productivity making the aquatic system highly sensitive to $P$ contamination. Some of the common sources of $P$ into the environment include phosphate-containing geologic formations, agricultural fertilizer application, detergent usage and industrial wastes ${ }^{8,9,10}$. This calls for constant monitoring of $P$ in water systems and other vulnerable environmental systems.

Several forms of $\mathrm{P}$ including orthophosphate (reactive phosphate), condensed phosphate (pyro-, meta- and polyphosphate) and organic phosphate may exist in natural waters ${ }^{11}$. These $P$ forms can be determined either partially or fully as the orthophosphate which is the most thermodynamically stable phosphate form ${ }^{12}$. Various analytical techniques have been reported for the determination of phosphate concentrations in water systems including titrimetric, complexogravimetric, atomic absorption spectrophotometry ${ }^{13}$, high performance liquid chromatography ${ }^{14}$, colorimetry ${ }^{15,16}$, and UV-Vis spectrophotometric methods ${ }^{17,18}$. Among the popular spectrophotometric methods of orthophosphate determination is the molybdenum blue $^{19}$ and the yellow vanadomolybdate complex methods of which the most commonly used is the molybdenum blue method due to its high sensitivity ${ }^{20}$. This method involves condensation of molybdate with orthophosphate in aqueous acidic medium forming 12-molybdophosphoric acid which is selectively reduced to the phosphomolybdate anion (molybdenum blue) as shown in equations 1 and 2. The intensity of the blue coloured heteropoly compound is proportional to the amount of $\mathrm{P}$ present in the sample.

$7 \mathrm{PO}_{4}^{3-}+12\left[\mathrm{Mo}_{7} \mathrm{O}_{24}\right]^{6-}+72 \mathrm{H}^{+} \rightarrow 7\left[\mathrm{PMO}_{12} \mathrm{O}_{40}\right]^{3-}+$ $3 \mathrm{H}_{2} \mathrm{O}$

$2\left[\mathrm{PMo}_{12} \mathrm{O}_{40}\right]^{3-}+$ reductant $\rightarrow \mathrm{PMo}^{(\mathrm{VI})}{ }_{12-\mathrm{x}} \mathrm{Mo}_{\mathrm{x}}^{(\mathrm{V} \text { or IV })}+$ $3 \mathrm{H}_{2} \mathrm{O}$

The molybdenum blue method since its introduction by Dickman and Bray, $1940^{21}$ has undergone several modifications to improve sensitivity, precision and selectivity for orthophosphate determination. Notably, improvements have been attempted through the use of various reductants such as tin(II) chloride ${ }^{22}$, ascorbic acid ${ }^{23}$, hydrazine sulphate, sodium sulphide ${ }^{18}$ and hydroquinone ${ }^{24}$. However, most of the modified methods have disadvantages such as instability of the heteropoly blue colour, interference from arsenic and copper, the lengthy time required for full colour development, low sensitivity coupled with high absorption by the blank $^{25}$. The rate of colour development is specifically slow with ascorbic acid, the most commonly used reductant employed in the Murphy and Riley, 1962 method $^{12}$, whereas hydrazine sulphate another preferred reductant is toxic and corrosive ${ }^{26}$. Besides, some of the modified methods are cumbersome and involve lengthy extraction procedures which require additional analyst skills ${ }^{18,27}$. Therefore, the use of sodium thiosulphate was explored as a reductant.

In this study, we demonstrate the determination of low levels of the orthophosphate anion as molybdenum blue using sodium thiosulphate the reducing agent. The sodium thiosulphate used to reduce molybdophosphoric acid to molybdenum blue is commercially available, cheap and a common laboratory reagent used in several redox reactions. It has been used in molybdenum blue reactions to counter arsenate interference by reducing $A s(V)$ to As (III) ${ }^{28}$ but it has not been optimized and reported for the orthophosphate determination. Moreover, the sodium thiosulphate solution is stable for several days as opposed to ascorbic acid the most commonly used reductant.

\section{MATERIALS AND METHODS}

\section{Materials}

All chemicals were of analytical grade and used without further purification. They included; sodium thiosulphate pentahydrate (Merck, RSA, 99.0-101.0\%), potassium dihydrogen phosphate (Merck, RSA 99.5\%), hydrochloric acid (Merck, RSA, 32\%), ammonium molybdate tetrahydrate (Sigma-Aldrich, RSA, $\geq 99 \%$ ), antimony potassium tartrate (Hopkin and Williams, England), L-ascorbic acid (BDH, England 99.0-100.5\%), glacial acetic acid (Merck, RSA, 98\%), sulphuric acid, sodium carbonate anhydrous, starch soluble (BDH, England), potassium iodate (Merck, RSA, 99.0-101.0\%), oxalic 
acid, potassium chloride, sodium sulphate (May and Baker Ltd, England), copper metal (Trust chemical laboratories, 99.5\%), sodium arsenate, lead(II) nitrate and sodium nitrite.

\section{Instrumental analysis}

The weighing was carried out using RADWAG Wagi Elektroniczne analytical balance (Model AS220.R2). The UV-Vis spectra were scanned using UV-VIS-NIR spectrophotometer (Shimadzu UV-3600) with $1 \mathrm{~cm}$ quartz cuvettes. The scanning wavelength was in the range of $500-1100 \mathrm{~nm}$.

\section{Preparation of solutions} solutions.

Deionized water was used to prepare all

\section{Stock and working standard orthophosphate solutions}

Stock orthophosphate solution was prepared by dissolving $\mathrm{KH}_{2} \mathrm{PO}_{4}(0.4393 \mathrm{~g})$ in deionized water to make a solution of $0.1 \mathrm{mg} \mathrm{P} \mathrm{mL}^{-1}$. The working orthophosphate standard solution (0.01

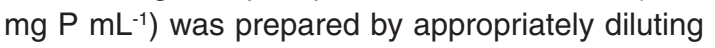
the stock phosphate solution.

\section{Sulphuric acid solution}

Sulphuric acid solution (0.5 M, 2.5 M and $5.5 \mathrm{M}$ ) was prepared by appropriately diluting concentrated $\mathrm{H}_{2} \mathrm{SO}_{4}(18.38 \mathrm{M})$.

\section{Ethanoic acid solution}

Ethanoic acid $(0.5 \mathrm{M})$ was prepared by appropriately diluting glacial acetic acid (17.398 M).

\section{Sodium thiosulphate solution}

Sodium thiosulphate $\left(\mathrm{Na}_{2} \mathrm{~S}_{2} \mathrm{O}_{3} \cdot 5 \mathrm{H}_{2} \mathrm{O}, 7.50\right.$ g) and $\mathrm{Na}_{2} \mathrm{CO}_{3}(0.0301 \mathrm{~g})$ were dissolved in $250 \mathrm{~mL}$ of recently boiled and cooled deionized water. The solution was standardized with $\mathrm{KIO}_{3}$ as follows: $\mathrm{KI}$ $(2.00 \mathrm{~g})$ was dissolved in deionized water $(25 \mathrm{~mL})$ and $\mathrm{HCl}(6 \mathrm{M}, 2 \mathrm{~mL})$ added followed by $\mathrm{KIO}_{3}(0.120$ g). The liberated iodine solution was then titrated with $\mathrm{Na}_{2} \mathrm{~S}_{2} \mathrm{O}_{3}$ solution until the triiodide complex was less intense. Starch indicator $(5 \mathrm{~mL})$ was added and the titration continued until a dark blue colour of the starch-triiodide complex turned colourless. The titration was repeated three times.

\section{Ascorbic acid solution}

Ascorbic acid $\left(\mathrm{C}_{6} \mathrm{H}_{8} \mathrm{O}_{6}, 1.760 \mathrm{~g}\right)$ was dissolved in deionized water $(100 \mathrm{~mL})$ to give a concentration of $0.1 \mathrm{M}$.

\section{Ammonium molybdate solution}

Ammonium molybdate, $\left(\mathrm{NH}_{4}\right)_{6} \mathrm{Mo}_{7} \mathrm{O}_{24}$ $.4 \mathrm{H}_{2} \mathrm{O}(4.00 \mathrm{~g})$ was dissolved in deionized water $(100 \mathrm{~mL})$ to make a $0.0324 \mathrm{M}$ solution.

\section{Antimony potassium tartrate solution}

Antimony potassium tartrate (KSbO. $\mathrm{C}_{4} \mathrm{H}_{4} \mathrm{O}_{6}, 0.2740 \mathrm{~g}$ ) was dissolved in deionized water $(100 \mathrm{~mL})$ to make an $8.4326 \times 10^{-3} \mathrm{M}$ solution.

\section{Ammonium molybdate-antimonyl tartrate (AM- PAT) solution}

The ammonium molybdate-antimonyl potassium tartrate (AM-PAT) solution was prepared by dissolving $\left(\mathrm{NH}_{4}\right)_{6} \mathrm{Mo}_{7} \mathrm{O}_{24} \cdot 4 \mathrm{H}_{2} \mathrm{O}(2.00 \mathrm{~g})$ and $\mathrm{KSbO}$. $\mathrm{C}_{4} \mathrm{H}_{4} \mathrm{O}_{6}(0.050 \mathrm{~g})$ in deionized water $(250 \mathrm{~mL})$. The AM-PAT solution was $6.473 \times 10^{-3} \mathrm{M}$ in ammonium molybdate and $6.1552 \times 10^{-4} \mathrm{M}$ in antimonyl potassium tartrate.

\section{Combined reagent}

Antimonyl potassium tartrate solution (8.4326 $\left.\times 10^{-3} \mathrm{M}, 5 \mathrm{~mL}\right)$ was added to dilute $\mathrm{H}_{2} \mathrm{SO}_{4}$ $(2.5 \mathrm{M}, 50 \mathrm{~mL})$ in a beaker followed by ammonium molybdate solution $(0.0324 \mathrm{M}, 15 \mathrm{~mL})$ and ascorbic acid solution $(0.1 \mathrm{M}, 30 \mathrm{~mL})$.

\section{Orthophosphate anion analytical method development}

To $50 \mathrm{~mL}$ volumetric flask was added the working orthophosphate solution, $\mathrm{KH}_{2} \mathrm{PO}_{4}(0.05 \mathrm{mg}$ $\mathrm{P} \mathrm{mL}-1,1 \mathrm{~mL})$, AM-PAT solution (4 mL), sulphuric acid $(5.5 \mathrm{M}, 1 \mathrm{~mL})$ and $\mathrm{Na}_{2} \mathrm{~S}_{2} \mathrm{O}_{3}$ solution $(0.1192 \mathrm{M}, 1 \mathrm{~mL})$. The solutions were made to the mark with deionized water. The solution was allowed to stand for $10 \mathrm{~min}$ and then the spectrum scanned against deionized water as a blank in the range $500-1100 \mathrm{~nm}$. Based on the spectrum, a maximum absorption $\left(\lambda_{\max }\right)$ of the reduced phosphopolyoxomolybdate complex was utilized in the subsequent analysis.

\section{Optimisation of the sodium thiosulphate molybdenum blue method}

Experimental parameters such as the concentration of various reagents and their order of addition were studied separately and the absorbance of the coloured product observed at $880 \mathrm{~nm}$. The optimization of the different parameters is presented in the proceeding sections. 
Determination of concentration of ammonium molybdate-potassium antimony tartrate for use

In this setup, a varying amount of the AM-PAT solution was utilized to study the effect of concentration of ammonium molybdate on the formation of phosphomolybdenum blue (PMB) complex in the presence of potassium antimony tartrate as a catalyst. To three separate $50 \mathrm{~mL}$ volumetric flasks was added $\mathrm{KH}_{2} \mathrm{PO}_{4}$ solution (0.05 mg P mL-1, $1 \mathrm{~mL}$ ), AM-PAT solution (2-10 $\mathrm{mL})$, followed by $\mathrm{H}_{2} \mathrm{SO}_{4}(5.5 \mathrm{M}, 1 \mathrm{~mL})$ and $\mathrm{Na}_{2} \mathrm{~S}_{2} \mathrm{O}_{3}$ solution $(0.1192 \mathrm{M}, 1 \mathrm{~mL})$. The solutions were made to the mark with deionized water, allowed to stand for $10 \mathrm{~min}$ and the absorbance of the resultant molybdenum blue complex measured at $880 \mathrm{~nm}$ against a reagent blank.

\section{Determination of concentration of the acid for use}

To each of three separate $50 \mathrm{~mL}$ volumetric flasks was added $\mathrm{KH}_{2} \mathrm{PO}_{4}$ solution $(0.05 \mathrm{mg} \mathrm{P} \mathrm{mL}$ ${ }^{1}, 1 \mathrm{~mL}$ ), an optimized volume of AM-PAT solution, sulphuric acid (5.5M, $0.25-2 \mathrm{~mL}$ ) and $\mathrm{Na}_{2} \mathrm{~S}_{2} \mathrm{O}_{3}$ solution $(0.1192 \mathrm{M}, 1 \mathrm{~mL})$. The solutions were diluted to the mark with deionized water, allowed to stand for $10 \mathrm{~min}$ and the absorbance of the molybdenum blue complex measured at $880 \mathrm{~nm}$ against a reagent blank.

Following the same procedure used for $\mathrm{H}_{2} \mathrm{SO}_{4}, \mathrm{HCl}$ and $\mathrm{CH}_{3} \mathrm{COOH}$ were also used to determine the acid to be used. The different solutions were allowed to stand for $10 \mathrm{~min}$ and the absorbance of the resultant molybdenum blue complexes measured at $880 \mathrm{~nm}$.

Influence of concentration of sodium thiosulphate reducing agent on molybdenum blue formation

The influence of the concentration of $\mathrm{Na}_{2} \mathrm{~S}_{2} \mathrm{O}_{3}$ reducing agent on the absorbance of the molybdenum blue complex was studied by utilizing varying volumes of the reductant. To three separate volumetric flasks was added $\mathrm{KH}_{2} \mathrm{PO}_{4}$ solution $(0.05$ $\mathrm{mg} \mathrm{P} \mathrm{mL}^{-1}, 1 \mathrm{~mL}$ ) followed by the optimized volumes of AM-PAT and $\mathrm{H}_{2} \mathrm{SO}_{4}$ and the reducing agent $\mathrm{Na}_{2} \mathrm{~S}_{2} \mathrm{O}_{3}(0.1192 \mathrm{M}, 0.25-2 \mathrm{~mL})$. The solutions were made to the mark with deionized water, allowed to stand for $10 \mathrm{~min}$ and the absorbance measured at $880 \mathrm{~nm}$ against a reagent blank.

\section{Order of reagent addition}

The effect of the order of addition of the reagents on the absorbance of the molybdenum blue complex was studied using optimized volumes of different reagents. The addition order of different solutions including $\mathrm{KH}_{2} \mathrm{PO}_{4}$, AM-PAT, $\mathrm{H}_{2} \mathrm{SO}_{4}$ and $\mathrm{Na}_{2} \mathrm{~S}_{2} \mathrm{O}_{3}$ was varied and the absorbance of the resultant molybdenum blue complex measured at $880 \mathrm{~nm}$.

\section{Colour stability of reduced phosphopoly- oxomolybdate complexes}

The colour stability of the reduced phosphomolybdate complex was studied using optimized volumes and addition order of the reagents. To three different $50 \mathrm{~mL}$ volumetric flasks was added $\mathrm{KH}_{2} \mathrm{PO}_{4}$ solution (0.05 mg P mL-1, 1 $\mathrm{mL}$ ) followed by addition of the colour developing agent comprised of AM-PAT, $\mathrm{H}_{2} \mathrm{SO}_{4}$ and $\mathrm{Na}_{2} \mathrm{~S}_{2} \mathrm{O}_{3}$. The absorbance of the resultant molybdenum blue complex was measured at $880 \mathrm{~nm}$ against a reagent blank immediately after mixing the solutions, and at regular intervals for 3600 seconds.

\section{Proposed procedure of orthophosphate anion determination}

The AM-PAT solution ( $6 \mathrm{~mL}), \mathrm{H}_{2} \mathrm{SO}_{4}(5.5 \mathrm{M}$, $1 \mathrm{~mL}$ ) and $\mathrm{Na}_{2} \mathrm{~S}_{2} \mathrm{O}_{3}$ solution $(0.1192 \mathrm{M}, 1.5 \mathrm{~mL})$ were added to standard phosphate solutions $(0.05 \mathrm{mg} \mathrm{P}$ $\left.\mathrm{mL}^{-1}\right)$. The solution was made up to the mark with deionized water and allowed to stand for $20 \mathrm{~min}$ for maximum colour development. The absorbance was measured at $880 \mathrm{~nm}$ against deionized water as the reagent blank. The amount of orthophosphate $\left(\mathrm{PO}_{4}{ }^{3-}\right)$ in $\mathrm{mg} \mathrm{P} \mathrm{mL}^{-1}$ was determined from the absorbances of the solutions.

\section{Method Validation}

The developed sodium thiosulphate molybdenum blue method for $\mathrm{PO}_{4}{ }^{3-}$ anion determination was validated according to the International Conference for Harmonisation (ICH) guidelines ${ }^{29}$ under the optimized experimental conditions to determine detection limits, linearity, accuracy, precision, and recovery.

\section{Determining detection and quantification limits}

The LoD and LoQ of this method were determined from standard deviation (SD) of intercepts of calibration curves obtained from replicate measurements of six blanks containing only the colour developing reagents without phosphorus. Then LoD and LoQ were calculated using the equations below ${ }^{29}$. 


$$
\begin{aligned}
& L o D=\frac{3.3 S D}{\text { Slope of calibration curve }} \\
& L o Q=\frac{10 S D}{\text { Slope of calibration curve }}
\end{aligned}
$$

\section{Determination of linearity of the method}

The linearity of the proposed method was verified by studying absorbances of six concentrations of standard $\mathrm{KH}_{2} \mathrm{PO}_{4}$ solutions covering the range $(0.01,0.02,0.03,0.04,0.05$ and $0.06 \mathrm{mg} \mathrm{P} \mathrm{mL}^{-1}$ ). The absorption of each concentration was measured three times. The curve of absorbance against concentration was obtained by plotting and statistically by calculating the correlation coefficient of different concentrations and the blank in triplicate. The regression equation and correlation coefficient were determined.

\section{Determination of accuracy and precision of the method}

In this study, the absorption of three concentration levels $(0.008,0.02$ and $0.06 \mathrm{mg}$ $\mathrm{P} \mathrm{mL}-1$ ) of standard $\mathrm{KH}_{2} \mathrm{PO}_{4}$ solutions within the concentration range were measured and each of them was replicated six times to evaluate accuracy and precision of the proposed methods. Precision was determined as RSD and accuracy as mean relative error (\%MRE).

\section{Determination of recovery}

The accuracy of the developed method was further ascertained by carrying out recovery experiments. Deionized water was spiked with standard $\mathrm{KH}_{2} \mathrm{PO}_{4}$ solutions at two different levels that is 0.01 and $0.05 \mathrm{mg} \mathrm{P} \mathrm{mL}^{-1}$ in a $50 \mathrm{~mL}$ volumetric flask. AM-PAT solution $(6 \mathrm{~mL}), \mathrm{H}_{2} \mathrm{SO}_{4}(5.5 \mathrm{M}, 1 \mathrm{~mL})$ and $\mathrm{Na}_{2} \mathrm{~S}_{2} \mathrm{O}_{3}$ solution (0.1192 M, $1.5 \mathrm{~mL}$ ) were added and made up to the mark with deionized water. The absorbance of each solution and the blank was measured six times at $880 \mathrm{~nm}$. The amount of phosphorus recovered was determined from calibration equations and recovery reported as RSD.

\section{Determination of Sandell's sensitivity}

Serial dilutions of concentration range (0.01-0.06 $\mathrm{mg} \mathrm{P} \mathrm{mL}^{-1}$ ) were prepared from the working $\mathrm{KH}_{2} \mathrm{PO}_{4}$ standard solution and treated with AM-PAT solution ( $6 \mathrm{~mL}), \mathrm{H}_{2} \mathrm{SO}_{4}(5.5 \mathrm{M}, 1 \mathrm{~mL})$ and $\mathrm{Na}_{2} \mathrm{~S}_{2} \mathrm{O}_{3}$ solution $(0.1192 \mathrm{M}, 1.5 \mathrm{~mL})$. Each dilution was scanned six times at $880 \mathrm{~nm}$ and the absorbance was recorded. The mean absorbance at each concentration level was determined and Sandell's sensitivity calculated using Equation 5 as described by Rajendraprasad, Basavaiah and Vinay, (2010) ${ }^{30}$.

Sandell's sensitivity $=\frac{\text { Concentration }\left(\frac{\mu g}{100 \mathrm{~mL}}\right) \times 0.001}{\text { Absorbance }}$

\section{Determination of molar absorptivity}

A series of phosphate concentrations in the range $\left(0.01-0.06 \mathrm{mg} \mathrm{P} \mathrm{mL}^{-1}\right)$ were prepared from the working $\mathrm{KH}_{2} \mathrm{PO}_{4}$ standard solution and treated with AM-PAT solution $(6 \mathrm{~mL}), \mathrm{H}_{2} \mathrm{SO}_{4}(5.5$ $\mathrm{M}, 1 \mathrm{~mL})$ and $\mathrm{Na}_{2} \mathrm{~S}_{2} \mathrm{O}_{3}$ solution $(0.1192 \mathrm{M}, 1.5 \mathrm{~mL})$. The absorbance of each solution was measured six times at $880 \mathrm{~nm}$. Molar absorptivity was determined using Equation 6.

$A=\varepsilon c d$

(Where $A=$ absorbance, $\varepsilon=$ molar absorptivity, $\mathrm{C}=$ concentration of absorbing species per unit volume $\left(\mathrm{mol} \mathrm{L}^{-1}\right), \mathrm{d}=$ path length $\left.(\mathrm{cm})\right)$.

\section{Evaluation of selectivity}

Some ions and organic acids exist in water together with the orthophosphate affecting its determination. The interference due to the presence of arsenate, chloride, oxalic acid, nitrite, sulphate and copper(II) ions was also studied. In the study, salts containing interfering ionic species were dissolved in deionized water to make a $100 \mathrm{mg}$ $\mathrm{L}^{-1}$ interferent solution. The solutions of interfering species ( $1 \mathrm{~mL}$ and $5 \mathrm{~mL}$ ) were transferred to 50 $\mathrm{mL}$ volumetric flasks containing $1 \mathrm{~mL}$ of standard $\mathrm{KH}_{2} \mathrm{PO}_{4}$ solutions $\left(0.04\right.$ and $\left.0.1 \mathrm{mg} \mathrm{P} \mathrm{mL}^{-1}\right)$. To the mixtures was added AM-PAT solution $(6 \mathrm{~mL}), \mathrm{H}_{2} \mathrm{SO}_{4}$ $(5.5 \mathrm{M}, 1 \mathrm{~mL})$ and $\mathrm{Na}_{2} \mathrm{~S}_{2} \mathrm{O}_{3}$ solution $(0.1192 \mathrm{M}, 1.5$ $\mathrm{mL}$ ) and the solutions were then made up to the mark with deionized water. The absorbances of the resulting solutions were determined in triplicate in the presence and absence of an interferent at 880 $\mathrm{nm}$ against deionized water.

Application of the developed sodium thiosulphate molybdenum blue method in the determination of the orthophosphate in selected water systems

The optimized molybdenum blue method based on sodium thiosulphate as the reductant was applied in the determination of $\mathrm{PO}_{4}{ }^{3-}$ in selected water systems and compared with the Murphy and 
Riley method. Water samples including distilled water and tap water collected from the laboratory together with environmental water samples collected from Makerere Kikoni channel $\left(0^{\circ} 20^{\prime} 07.3^{\prime \prime} \mathrm{N} 32^{\circ} 33^{\prime} 38.0^{\prime \prime} \mathrm{E}\right)$, Kiwunya channel $\left(0^{\circ} 19^{\prime} 42.4^{\prime \prime} \mathrm{N} 32^{\circ} 33^{\prime} 44.9^{\prime \prime} \mathrm{E}\right)$ and Nanfumbambi well $\left(0^{\circ} 19^{\prime} 54.8^{\prime \prime} \mathrm{N} 32^{\circ} 33^{\prime} 46.2^{\prime \prime} \mathrm{E}\right)$ in Kampala City-Uganda. The environmental sampling sites are located within a busy Kampala suburb where both residential and business human activities are carried out. The water samples were filtered through Whatman membrane filters $(0.45 \mu \mathrm{m}$ pore size $)$. The first $10 \mathrm{~mL}$ of the filtrate of each sample was rejected and the remainder collected in labelled sample bottles for determination of $\mathrm{PO}_{4}{ }^{3-}$ using the optimized method as previously described. The samples were appropriately diluted before analysis except for the distilled water and tap water samples.

\section{RESULTS AND DISCUSSION}

\section{Determination of absorption maxima for the} phosphomolybdenum blue

The spectrophotometric method described herein involves the formation of 12-molybdophosphoric acid on condensation of the molybdate and phosphate in aqueous sulphuric acid medium followed by its reduction with sodium thiosulphate to form a phosphomolybdenum blue complex (PMB).

When the absorbance of the resultant phosphomolydenum blue (PMB) complex was scanned from $500 \mathrm{~nm}$ to $1100 \mathrm{~nm}$, significant absorption was observed at $880 \mathrm{~nm}$ and $721 \mathrm{~nm}$ as shown in Fig. 1. Therefore, the wavelength of $880 \mathrm{~nm}$ at which the PMB complex exhibited the highest absorbance was selected as the $\lambda_{\max }$ for the determination and was utilized in all subsequent measurements.

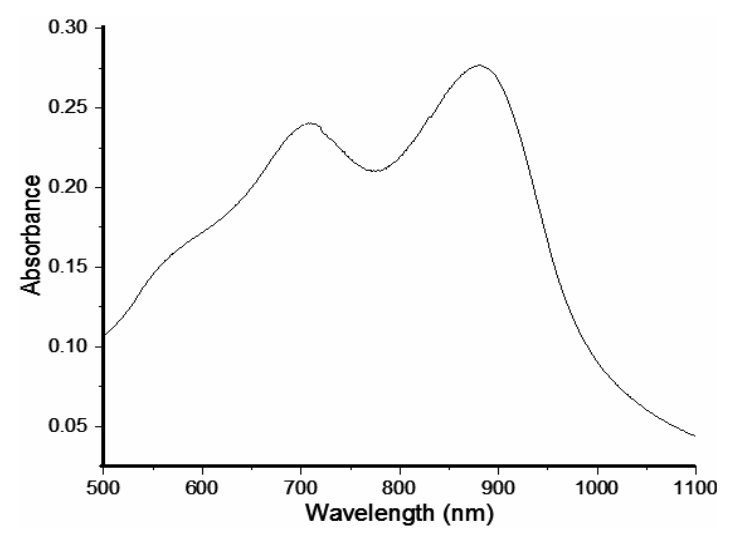

Fig. 1. Absorption spectrum of the sodium thiosulphate reduced phosphomolybdenum blue complex
Optimisation of the formation and stability of the phosphomolybdenum blue complex

The experimental conditions for the formation of PMB were optimized, by studying their effect on the intensity and stability of the final molybdenum blue colour, for the effective determination of the $\mathrm{PO}_{4}{ }^{3-}$ anion in waters.

Effect of concentration of ammonium molybdate-potassium antimonyl tartrate on phosphomolybdenum blue formation

The effect of concentration of ammonium molybdate and antimonyl potassium tartrate catalyst on PMB formation was investigated with varying volumes of AM-PAT solution. A plot of absorbance of solutions treated with varying volumes of AM-PAT solution shown in Fig. 2 shows that the absorbance values increased with the increasing volume of AMPAT, with maximum absorbance being achieved after addition of $6 \mathrm{~mL}$ of AM-PAT solution. The solution was $6.473 \times 10^{-3} \mathrm{M}$ in ammonium molybdate and $6.1552 \times 10^{-4} \mathrm{M}$ in antimonyl potassium tartrate. When the volume of AM-PAT was higher than $6 \mathrm{~mL}$, the absorbance was found to decrease. Therefore, $6 \mathrm{~mL}$ of AM-PAT was used in subsequent procedures for phosphate determination.

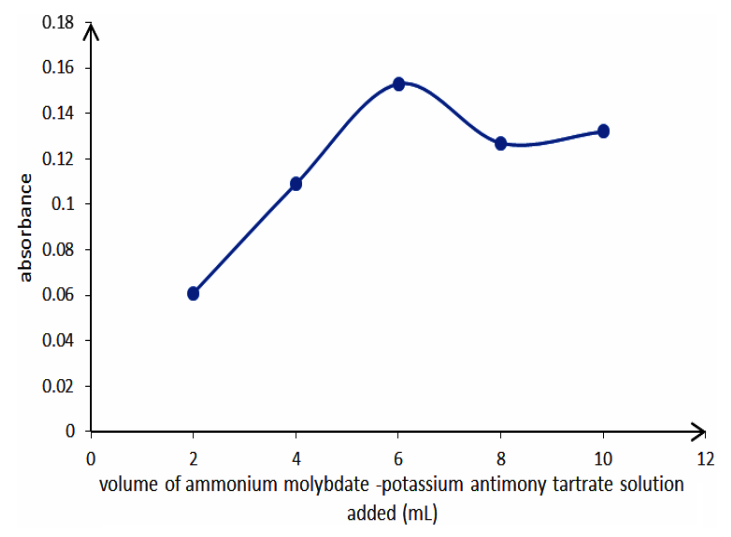

Fig. 2. Effect of different volumes of ammonium molybdateantimonyl potassium tartrate solution + phosphate (0.05 mg P mL-1, $1 \mathrm{~mL})+\mathrm{H}_{2} \mathrm{SO}_{4}(5.5 \mathrm{M}, 1 \mathrm{~mL})+\mathrm{Na}_{2} \mathrm{~S}_{2} \mathrm{O}_{3}$ solution $(0.1192 \mathrm{M}, 1 \mathrm{~mL})$ diluted to $50 \mathrm{~mL}$ with water

Effect of acid concentration on phosphomolybdenum blue formation

The effect of the concentration of $\mathrm{H}_{2} \mathrm{SO}_{4}$ on the absorbance of the resultant phosphomolybdenum blue was studied by using various volumes of $5.5 \mathrm{M}$ $\mathrm{H}_{2} \mathrm{SO}_{4}$ in combination with the optimised volume of AM-PAT. The results of this study presented in Fig. 3 , show that the solution containing $1 \mathrm{~mL}$ of 
$5.5 \mathrm{M} \mathrm{H}_{2} \mathrm{SO}_{4}$ produced phosphomolydenum blue with the highest absorbance at $880 \mathrm{~nm}$. From the graph, it can be observed that as acidity increased beyond the optimal value, the absorbance reduced. A similar observation was made by Pradhan and Pokhrel, $(2013)^{29}$. Therefore, a volume of $1 \mathrm{~mL}$ of $5.5 \mathrm{M} \mathrm{H}_{2} \mathrm{SO}_{4}$ was used throughout the experiments for $\mathrm{PO}_{4}^{3-}$ determination.

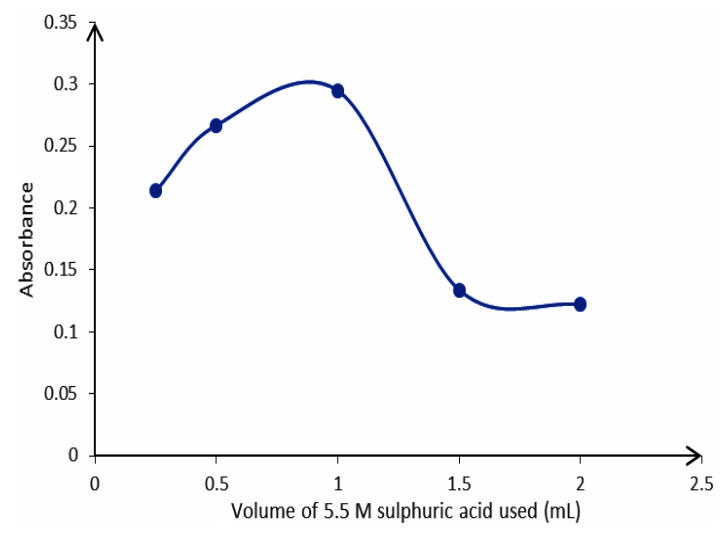

Fig. 3. Effect of different volumes of sulphuric acid (5.5 M, 0.25-2mL) + phosphate (0.05 $\left.\mathrm{mg} \mathrm{P} \mathrm{mL}^{-1}, 1 \mathrm{~mL}\right)$ + AM-PAT solution $(6 \mathrm{~mL})+\mathrm{Na}_{2} \mathrm{~S}_{2} \mathrm{O}_{3}$ solution $(0.1192 \mathrm{M}, 1 \mathrm{~mL})$ diluted to $50 \mathrm{~mL}$ with water

Effect of type of acid on the absorbance of the phosphomolybdenum blue

The formation of the PMB takes place in acidic medium and it was relevant to determine the most suitable acid for the orthophosphate determination. Under this study, different acids including $\mathrm{H}_{2} \mathrm{SO}_{4}, \mathrm{HCl}$ and $\mathrm{CH}_{3} \mathrm{COOH}$ were tested using equimolar and similar volumes of the respective acids. The results presented in Table 1 show that the highest absorbance was attained for solutions acidified with $\mathrm{HCl}$ followed by $\mathrm{H}_{2} \mathrm{SO}_{4}$ whereas $\mathrm{CH}_{3} \mathrm{COOH}$ exhibited the lowest absorbance. Thus, acidification of solutions for phosphate determination by the molybdenum blue method could be carried out with $\mathrm{HCl}$ or $\mathrm{H}_{2} \mathrm{SO}_{4}$ but the former was rejected over the salt error caused by chloride interference, which results into a high standard deviation in the observed readings as reported by Nagul et al., (2015) ${ }^{28}$.

Table 1: Effect of the type of acid on the determination of the orthophosphate ion

\begin{tabular}{ccc}
\hline Entry & Type of acid & Absorbance \pm RSD\% \\
\hline 1 & Sulphuric acid & $0.195 \pm 6.70 \%$ \\
2 & Hydrochloric acid & $0.206 \pm 17.78 \%$ \\
3 & Acetic acid & $0.011 \pm 45.05 \%$ \\
\hline
\end{tabular}

The value is an average of 6 replicates
Effect of concentration of reducing agent on phosphomolybdenum blue formation

The effect of $\mathrm{Na}_{2} \mathrm{~S}_{2} \mathrm{O}_{3}$ concentration on the formation of $\mathrm{PMB}$ was investigated by observing the absorbance of the PMB with varying amounts of the reductant. The absorbance of $\mathrm{PMB}$ increased with increasing volumes of $0.1192 \mathrm{M} \mathrm{Na}_{2} \mathrm{~S}_{2} \mathrm{O}_{3}$ with maximum absorbance obtained on adding $1.5 \mathrm{~mL}$ of $\mathrm{Na}_{2} \mathrm{~S}_{2} \mathrm{O}_{3}$ as shown in Fig. 4. An increase in the amount of $\mathrm{Na}_{2} \mathrm{~S}_{2} \mathrm{O}_{3}$ beyond the optimal volume resulted in a reduction in the absorbance of $\mathrm{PMB}$. Therefore, a volume of $1.5 \mathrm{~mL} \mathrm{Na} \mathrm{S}_{2} \mathrm{O}_{3}$ was used in the subsequent experiments.

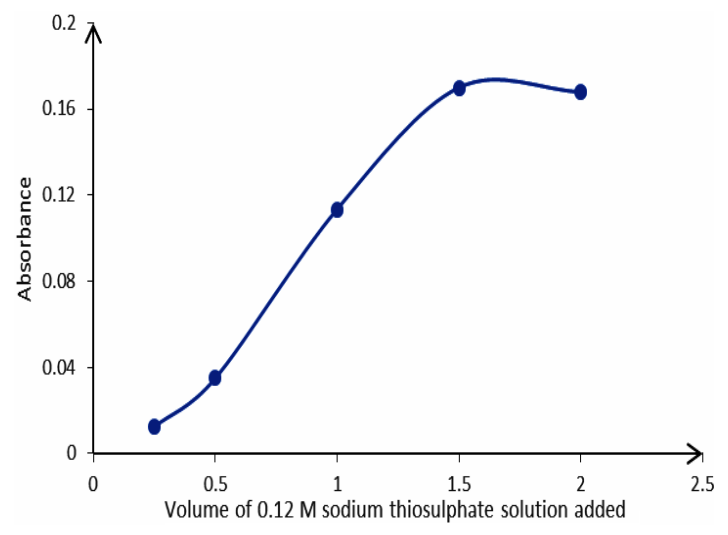

Fig. 4. Effect of different volumes of $\mathrm{Na}_{2} \mathrm{~S}_{2} \mathrm{O}_{3}$ solution (0.1192 M, 0.5-2 mL) + phosphate (0.05 mg P mL-1,1 mL) + AM-PAT solution ( $6 \mathrm{~mL})$ + sulphuric acid $(5.5 \mathrm{M}, 1 \mathrm{~mL})$ diluted to $50 \mathrm{~mL}$ with water

Effect of order of addition of reagents on phosphomolybdenum blue formation

In this study, the optimized volumes of the various reagents were added in different orders and taken through the proposed method. The results obtained as presented in Table 2 indicate that the change in the order of reagent addition affects absorbance values of the solutions. It was observed that the order AM-PAT $+\mathrm{H}_{2} \mathrm{SO}_{4}+\mathrm{Na}_{2} \mathrm{~S}_{2} \mathrm{O}_{3}+\mathrm{PO}_{4}^{3-}$ registered the highest absorbance. However, the order was not adopted because it compromised the stability of the formed PMB. Moreover, the acid can decompose the $\mathrm{Na}_{2} \mathrm{~S}_{2} \mathrm{O}_{3}$ as shown in Equation 7. Also, the order $\mathrm{H}_{2} \mathrm{SO}_{4}+\mathrm{Na}_{2} \mathrm{~S}_{2} \mathrm{O}_{3}+\mathrm{PO}_{4}{ }^{3-}+\mathrm{AM}$ PAT, exhibited a higher standard deviation in the absorbance readings. Therefore, the order $\mathrm{PO}_{4}^{3-}+$ AM-PAT $+\mathrm{H}_{2} \mathrm{SO}_{4}+\mathrm{Na}_{2} \mathrm{~S}_{2} \mathrm{O}_{3}$ where the reductant is added last was followed.

$\mathrm{S}_{2} \mathrm{O}_{3}{ }^{2-}+2 \mathrm{H}^{+} \rightarrow \mathrm{SO}_{2}+\mathrm{S}+\mathrm{H}_{2} \mathrm{O}$

Effect of time on the formation of phosphomolybdenum blue

The rate of formation of phosphomolybdate 
is time dependent (Huang and Zhang, 2008) but is also affected by a catalyst. Murphy and Riley, (1962) used potassium antimonyl tartrate as a catalyst in the single solution method of phosphate determination in sea waters. The same method was adopted with modifications to develop the $\mathrm{Na}_{2} \mathrm{~S}_{2} \mathrm{O}_{3}$ molybdenum blue method of orthophosphate anion determination. As seen from the graphs in Fig. 5 the rate of colour development was faster in the catalyzed reaction, unlike the uncatalyzed one. The absorbance of the PMB increased steadily up to $20 \mathrm{~min}$ after which it increased slightly with time for $60 \mathrm{~min}$ studied. Thus, the optimal time lag after the addition of the reductant to the reading of the absorbance of the formed molybdenum blue complex was 20 minutes. This implies that the rate of molybdenum blue colour formation is slightly higher with ascorbic acid reductant compared to sodium thiosulphate, since the former requires $10 \mathrm{~min}$ to attain optimal colour development.

Table 2: Effect of order of reagents addition in the $\mathrm{Na}_{2} \mathrm{~S}_{2} \mathrm{O}_{3}$ molybdenum blue method

\begin{tabular}{cc}
\hline Order of addition & Absorbance \pm RSD $\%$ \\
\hline $\mathrm{PO}_{4}{ }^{3-}+\mathrm{AM}-\mathrm{PAT}+\mathrm{H}_{2} \mathrm{SO}_{4}+\mathrm{Na}_{2} \mathrm{~S}_{2} \mathrm{O}_{3}$ & $0.148 \pm 7.97 \%$ \\
$\mathrm{AM}-\mathrm{PAT}+\mathrm{H}_{2} \mathrm{SO}_{4}+\mathrm{Na}_{2} \mathrm{~S}_{2} \mathrm{O}_{3}+\mathrm{PO}_{4}^{3-}$ & $0.268 \pm 11.14 \%$ \\
$\mathrm{H}_{2} \mathrm{SO}_{4}+\mathrm{Na}_{2} \mathrm{~S}_{2} \mathrm{O}_{3}+\mathrm{PO}_{4}{ }^{3-}+\mathrm{AM}-\mathrm{PAT}$ & $0.217 \pm 26.33 \%$ \\
$\mathrm{Na}_{2} \mathrm{~S}_{2} \mathrm{O}_{3}+\mathrm{PO}_{4}{ }^{3-}+\mathrm{AM}-\mathrm{PAT}+\mathrm{H}_{2} \mathrm{SO}_{4}$ & $0.113 \pm 17.74 \%$ \\
\hline
\end{tabular}

Value is the average of three determinations for each order

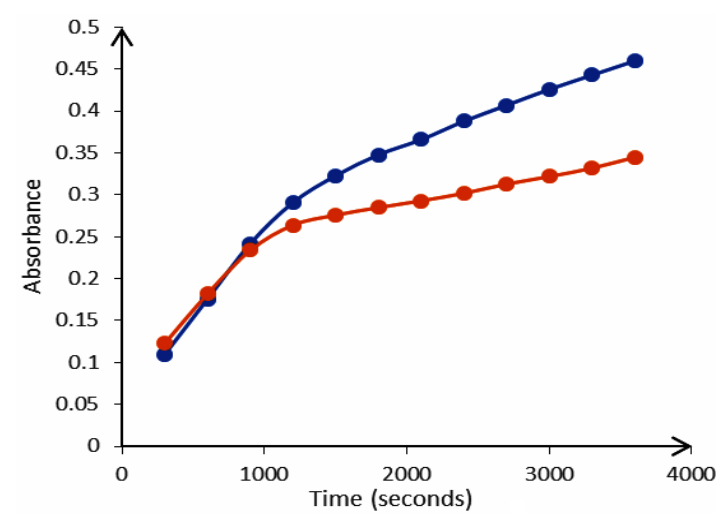

Fig. 5. Effect of time on the colour stability of $\mathrm{Na}_{2} \mathrm{~S}_{2} \mathrm{O}_{3}$ reduced phosphomolybdate solution

Validation of the sodium thiosulphate molybdenum blue method for orthophosphate determination Calibration curve and sensitivity

The calibration curve for orthophosphate analysis obtained by plotting absorbance as a function of the concentration of orthophosphate (in $\mathrm{mg} \mathrm{P} \mathrm{mL}^{-1}$ ) at $880 \mathrm{~nm}$ is shown in Fig. 6. The plot is linear in the range of $0.005-0.06 \mathrm{mg} \mathrm{P} \mathrm{mL}^{-1}$. The amount of orthophosphate within this range can be determined directly and for those above this range, the sample should be diluted. The molar absorptivity and Sandell's sensitivity determined from the calibration curve at $880 \mathrm{~nm}$ were $57526 \mathrm{~L} \mathrm{~mol}^{-1} \mathrm{~cm}^{-1}$ and 0.2835 $\mu \mathrm{g} \mathrm{cm}^{-2}$ respectively. The values were found to be within acceptable limits. The LoD and LoQ obtained using the proposed method in comparison to those achieved with the Murphy and Riley methods are presented in Table 3. The results show that the present method based on the sodium thiosulphate reductant offers a lower detection (LoD) and quantification (LoQ) limits compared to the commonly used Murphy and Riley method. This suggests that the sodium thiosulphate method can be used to determine low levels of $P$ in water systems.

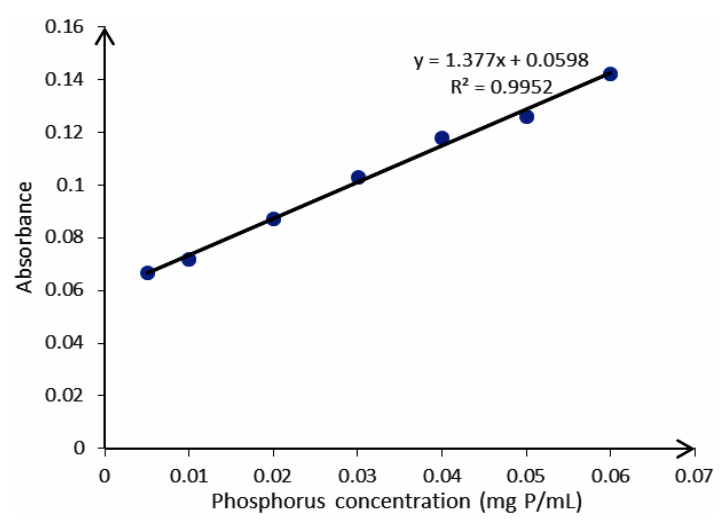

Fig. 6. Calibration curve for the determination of orthophosphate

Table 3: Comparison of detection limits obtained with the proposed method and the Murphy and Riley methods of orthophosphate determination

\begin{tabular}{ccc}
\hline Method & LoD $\left(\mathrm{mg} \mathrm{P} \mathrm{mL}^{-1}\right)$ & $\operatorname{LoQ}\left(\mathrm{mg} \mathrm{P} \mathrm{mL}^{-1}\right)$ \\
\hline $\begin{array}{ccc}\text { Murphy and Riley } \\
\text { Present }\end{array}$ & $8.31 \times 10^{-3}$ & 0.0252 \\
& $2.213 \times 10^{-3}$ & $5.538 \times 10^{-3}$ \\
\hline
\end{tabular}

$\mathrm{n}=6$ (average of six readings); LoD and $L o Q$ values of the Murphy and Riley method were calculated from experimentally determined values

\section{Accuracy and precision}

The precision of the method was determined by repeat analysis of samples at different concentrations and results were expressed as standard deviation (SD) and relative standard deviation (\%RSD). Results of the precision studies for 6 replicate determinations of different orthophosphate levels exhibited \%RSD values in the range 1.72 to $7.01 \%$ (Table 4). The RSD values of less than $20 \%$ are regarded as good indicating the method's repeatability when used for analysing orthophosphate levels in waters. The results obtained for replicate determinations of $0.008,0.02$ and $0.06 \mathrm{mg} \mathrm{P} \mathrm{mL}^{-1}$ phosphate were 
analysed by ANOVA. The F-critical 4.414 was less than the F-calculated 32.91, 32.77 and 32.29 for the respective concentrations. An indication that the results of the orthophosphate determination obtained using the present sodium thiosulphate molybdenum blue method are precise.

Table 4: Evaluation of precision of the $\mathrm{Na}_{2} \mathrm{~S}_{2} \mathrm{O}_{3}$ molybdenum blue method

\begin{tabular}{ccccc}
\hline Added concentration $\left(\mathrm{mg} \mathrm{P} \mathrm{mL}^{-1}\right)$ & Detected concentration $\left(\mathrm{mg} \mathrm{P} \mathrm{mL}^{-1}\right)$ & $\mathrm{MRE}(\%)$ & $\mathrm{SD}$ & $\mathrm{RSD}(\%)$ \\
\hline 0.008 & 0.0079 & 1.53 & $1.44 \times 10^{-4}$ & 1.84 \\
0.02 & 0.0187 & 6.75 & $1.31 \times 10^{-3}$ & 7.01 \\
0.06 & 0.0584 & 2.64 & $1.00 \times 10^{-3}$ & 1.72 \\
\hline
\end{tabular}

$\mathrm{n}=6$ (average of ten readings), MRE is mean relative error

In this study, the accuracy of the developed method was validated by calculating the mean percent recovery of spiked samples for six replicates at different concentration levels prepared from independent stock solutions. Recoveries above $90 \%$ were registered for the different concentration levels. The RSD values were within the acceptable range of less than $20 \%$ (Table 5). Therefore, this ably demonstrates that the present sodium thiosulphate molybdenum blue method is suitable for the determination of low levels of the orthophosphate and the results generated are accurate.

Table 5: Evaluation of accuracy of the $\mathrm{Na}_{2} \mathrm{~S}_{2} \mathrm{O}_{3}$ molybdenum blue method

\begin{tabular}{cc}
\hline Added concentration $\left(\mathrm{mg} \mathrm{P} \mathrm{mL}^{-1}\right)$ & Recovery \pm RSD\% \\
\hline 0.008 & $97.68 \pm 2.88$ \\
0.02 & $97.5 \pm 10.12$ \\
0.06 & $98.67 \pm 2.56$ \\
\hline
\end{tabular}

$\mathrm{n}=6$ (average of six readings)

\section{Effect of interfering substances}

The effect of interfering cations, anions and organic acids on phosphate determination using the developed sodium thiosulphate molybdenum blue method was also examined. In this study, ions that are known to affect the determination $\mathrm{PO}_{4}{ }^{3-}$ in water samples using the molybdenum blue methods were added to standard solutions and analysed using the present method. The results show that interferents affected the analysis differently.

The interference caused by arsenate ion is shown in Fig. 7. The absorbance of molybdenum blue solutions formed increased in presence of $\mathrm{AsO}_{4}{ }^{3-}$ (Fig. 7b). The $\mathrm{AsO}_{4}{ }^{3-}$ ion has a tetrahedral geometry like the orthophosphate and can undergo a similar reaction with molybdate forming heteropolyacids. Upon reduction, they form arsenomolybdenum blue species with an absorption maximum close to that of the phosphomolybdenum blue. Indeed, a previous study utilized the molybdenum blue method to determine $\mathrm{AsO}_{4}{ }^{3-}$ in natural water samples at 865 $\mathrm{nm}$ as shown in Fig. $7 \mathrm{a}^{32}$, which is likely to affect orthophosphate determination at $880 \mathrm{~nm}$. When $\mathrm{AsO}_{4}{ }^{3-}$ ions were introduced into in the reaction mixture, they interfered with phosphorus analysis causing a shift in the $\lambda_{\max }$. Investigations carried out at two orthophosphate levels $(0.04$ and 0.1 $\mathrm{mg} \mathrm{P} \mathrm{mL}^{-1}$ ) show that absorbance increased with increase in $\mathrm{AsO}_{4}{ }^{3-}$ concentrations. Therefore, $\mathrm{AsO}_{4}{ }^{3-}$ has positive interference on $\mathrm{PO}_{4}^{3-}$ determination. In this respect, in the analysis of water samples containing significant amounts of the arsenate using the present sodium thiosulphate molybdenum blue method, this interferent must be removed using standard procedures before determination of the orthophosphate. In contrast, $\mathrm{Cl}^{-}$ions exhibited negative interference in the orthophosphate determination possibly by decreasing the analytical signal since $\mathrm{Cl}^{-}$disrupts the formation of $\mathrm{PMB}^{28}$.
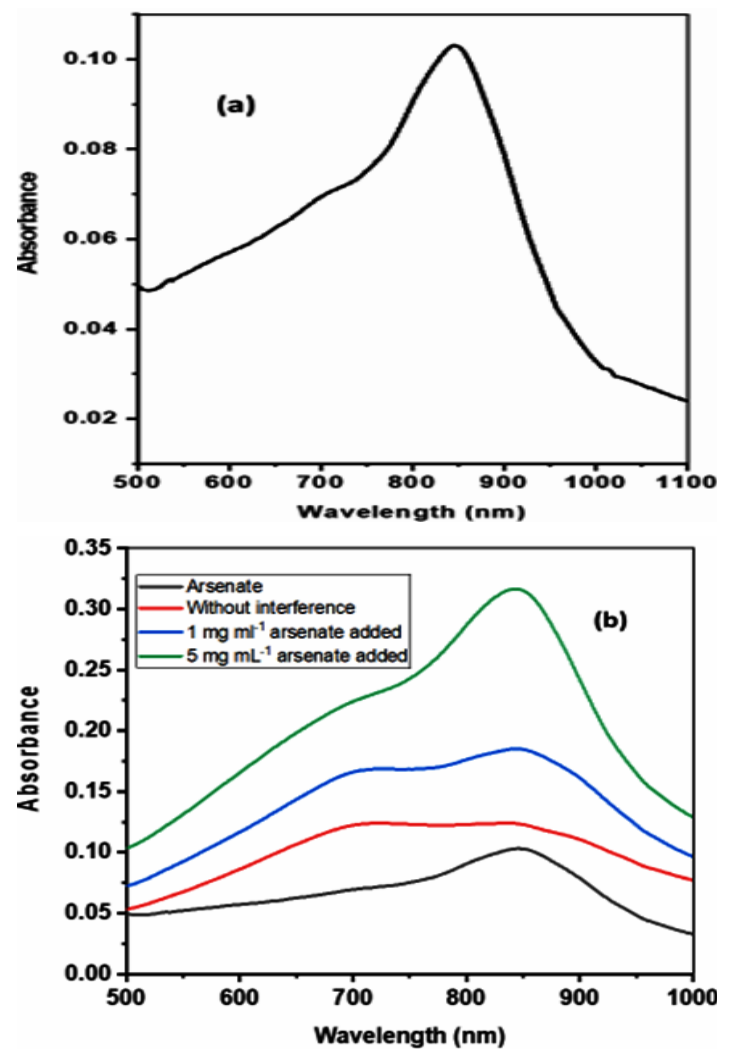

Fig. 7. Absorbance spectrum of arsenate ions (a), Effect of arsenate ions on molybdenum blue formation (b) 
Results of the investigation for the effect of oxalic acid on molybdenum blue formation are shown in Fig. 8. The results show a reduction in absorbance of PMB complex with increase in the oxalic acid concentrations. Generally, organic acids interfere in phosphomolybdenum blue methods by sequestering $\mathrm{Mo}(\mathrm{VI})$ and destroying 12-molybdophosphoric acid. This is possible because organic acids like oxalic acid coordinate in a bidentate manner with $\mathrm{Mo}(\mathrm{VI})$ to form a stable six membered complex ${ }^{33}$. This results in a reduction in the absorbance of the PMB.

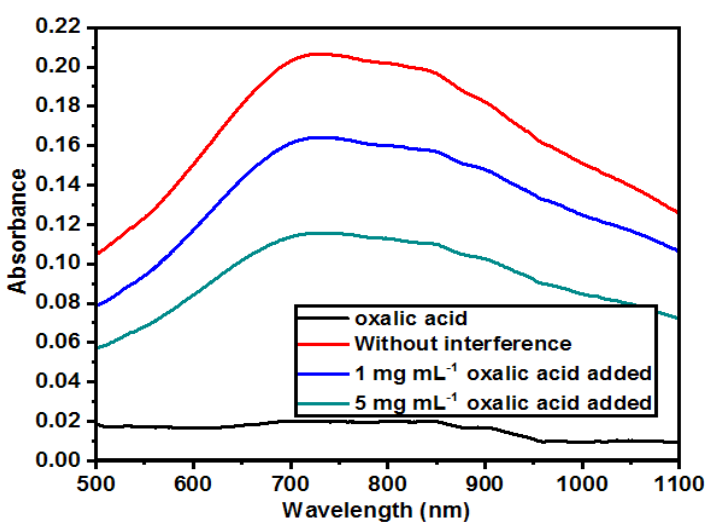

Fig. 8. Effect of oxalic acid on molybdenum blue formation

$\left[\mathrm{PMO}_{4}^{\mathrm{V}} \mathrm{Mo}_{8}^{\mathrm{VI}} \mathrm{O}_{40}\right]^{7-}+\mathrm{NO}_{2}-^{-} \rightarrow\left[\mathrm{PMO}^{\mathrm{VI}}{ }_{12} \mathrm{O}_{40}\right]_{3}{ }^{-}+\mathrm{NO}$

The effect of the nitrite ion on the molybdenum blue formation is shown in Fig. 9. Presence of the nitrite ion decreases the absorbance of the reduced phosphomolybdate complex. The nitrite ion is an oxidizing agent, thus, it oxidises molybdenum blue according to Equation 8 which is followed by a reduction in absorbance. Similar observations were made in the determination of nitrate and nitrite in water, meat products and vegetables using phosphomolybdenum blue method; a reduction in the intensity of the blue colour was proportional to nitrite content ${ }^{34}$.

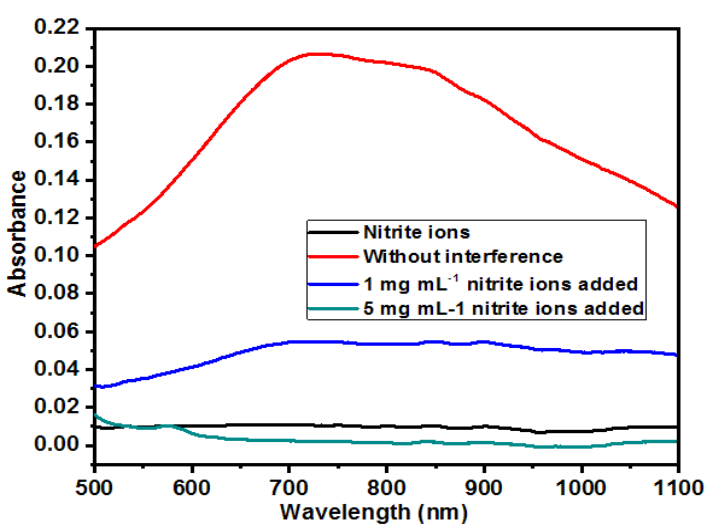

Fig. 9. Effect of nitrite on molybdenum blue formation
Results of the effect of copper (II) ions on molybdenum blue formation presented in Fig. 10, show that the absorbance of the complex decreased with increasing concentrations of $\mathrm{Cu}^{2+}$ ions added to $\mathrm{PO}_{4}{ }^{3-}$ solutions. The reduced absorbance could be a result of inhibition of $\mathrm{Mo}(\mathrm{VI})$ reduction which is caused by $\mathrm{Cu}^{2+}$ ions ${ }^{35,36}$. Like $\mathrm{Cu}^{2+}, \mathrm{Pb}^{2+}$ ions also inhibit $\mathrm{Mo}(\mathrm{VI})$ reduction leading to reduced intensity of molybdenum blue formed ${ }^{34}$.

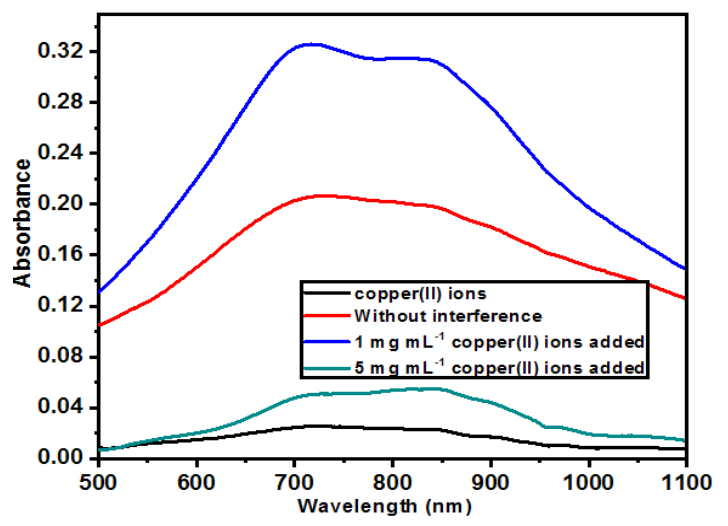

Fig. 10. Interference of $\mathrm{Cu}^{2+}$ ion on molybdenum blue formation

\section{Determination of levels of orthophosphate anion in selected water systems}

The developed sodium thiosulphate molybdenum blue method was applied in the determination of the orthophosphate in selected natural waters and the results are presented in Table 6. The results show that the $\mathrm{PO}_{4}{ }^{3-}$ was present in the different water samples in varying concentrations. Samples from Makerere Kikoni Channel and Kiwunya Channel exhibited higher levels of $P$ of 0.03 ppm and 0.028 ppm respectively. The high $\mathrm{PO}_{4}^{3-}$ concentration in water from these channels could be attributed to the various sources of phosphorus such as solid and liquid wastes generated from households, shops, restaurants and kiosks along the channel. Also, the animal excreta and pit latrines located in the vicinity discharge into the channel especially on rainy days. Moreover, there are several washing bays where youth use detergents some of which are $\mathrm{P}$ based, to wash motorcycles and bicycles. Further on, the elevated $P$ levels could also be due to natural decomposition of rocks and minerals, weathering of soluble inorganic materials and leaching of biomass ${ }^{37}$. On the other hand, the amount of orthophosphate in the distilled water and tap water samples were below detection limits. 
As shown in Table 6, the results obtained for $\mathrm{PO}_{4}{ }^{3-}$ determination in water samples using the present sodium thiosulphate method were compared to those obtained using the Murphy and Riley, 1962 method that employs ascorbic acid reducing agent. The results obtained for the different samples using the two methods are in agreement. The correlation of the two methods was found to be 0.996 for determination of $\mathrm{PO}_{4}^{3-}$ in five water samples. This demonstrates the applicability of the developed method for the accurate determination of the orthophosphate in environmental water samples.

Table 6: Determination of phosphate in water samples

\begin{tabular}{lcc}
\hline Sample & $\begin{array}{c}\text { Phosphate concentration } \\
\pm \mathrm{SD}\left(\mathrm{mg} \mathrm{P}^{-1}\right)\end{array}$ \\
& $\begin{array}{c}\text { Ascorbic acid } \\
\text { method }\end{array}$ & $\begin{array}{c}\mathrm{Na}_{2} \mathrm{~S}_{2} \mathrm{O}_{3} \\
\text { method }\end{array}$ \\
\hline $\begin{array}{l}\text { Distilled water } \\
\text { Tap water }\end{array}$ & $\mathrm{ND}$ & $\mathrm{ND}$ \\
Makerere Kikoni channel & $0.0336 \pm 0.001$ & $\mathrm{ND}$ \\
water & & $0.0300 \pm 0.05$ \\
Kiwunya channel water & $0.0316 \pm 0.0006$ & $0.0278 \pm 0.005$ \\
Nanfumbambi well water & $0.016 \pm 0.001$ & $0.0177 \pm 0.009$ \\
\hline
\end{tabular}

Results based on five measurements. ND = detected. SD = standard deviation

\section{CONCLUSION}

A simple and rapid spectrophotometric method for the determination of low levels of orthophosphate ions in water is reported. The method involves the reduction of phosphomolybdate complex formed by condensation of the molybdate and phosphate in an aqueous acid medium using $\mathrm{Na}_{2} \mathrm{~S}_{2} \mathrm{O}_{3}$ solution. The result is the formation of molybdenum blue which exhibited a maximum absorption at $880 \mathrm{~nm}$. The method is simple and cheap compared to other methods since it does not require sophisticated instruments or involve extraction of the analyte and the $\mathrm{Na}_{2} \mathrm{~S}_{2} \mathrm{O}_{3}$ reducing agent employed to reduce phosphomolybdate is a readily available laboratory chemical. The optimized method was successfully employed in the determination of $\mathrm{PO}_{4}^{3-}$ in water samples and the results of the analysis compared favourably with the Murphy and Riley, 1962 ascorbic acid method. Also, the present sodium thiosulphate molybdenum blue method exhibited low LoD and LoQ in the determination of the orthophosphate compared to the ascorbic acid molybdenum blue which is the most commonly used method for this analysis.

\section{ACKNOWLEDGEMENT}

The authors would like to acknowledge the Organisation for the Prohibition of Chemical Weapons (OPCW), the African-German Network of Excellence in Science (AGNES) and the German Academic Exchange Service (DAAD) for funding this study. The authors would also like to thank the International Science Programme (ISP), Uppsala University, Sweden, for funding some of the equipment used in the study. Support by the School of Chemistry and Physics, University of KwaZulu Natal-Westville, Departments of Chemistry, Mbarara University of Science and Technology and Department of Chemistry, Makerere University is also gratefully acknowledged.

\section{Conflict of Interest}

The authors declare that they have no conflict of interest.

\section{REFERENCES}

1. Greenwood, N.N.; Earnshaw, A.; Chemistry of the Elements (2 ${ }^{\text {nd }}$ ed.).;. Pergamon Press Ltd., 1997, 548.

2. Sharpley, A.; Daniel, T. C.; Sims, J. T.; Pote, D. $\mathrm{H}$.; Journal of Soil and Water Conservation., 1996, 51(2), 160-166.

3. Carpenter, S. R.; Caraco, N. F.; Correll, D. L.; Howarth, R. W.; Sharpley, A. N.; Smith, V. H.; Ecological Applications., 1998, 8(3), 559-568.

4. Bennett, E. M.; Carpenter, S. R.;Caraco, N.
F.; BioScience., 2001, 51(3), 227.

5. Carpenter, S. R.; Caraco, N. F.; Correll, D. L.; Howarth, R. W.; Sharpley, A. N.; Smith, V. H.; 2010, 8(January 1998), 559-568.

6. USEPA.; Quality Criteria for Water 1986. Office of Water Regulations and standards Washington, DC 20460., 1986, 235-243.

7. Chapman, D.; Water Quality Assessments - A Guide to Use of Biota, Sediments and Water in Environmental Monitoring. $2^{\text {nd }}$ ed.; Great Britain: E \&FN Spon., 1996, 95-97. 
8. Gales, M. E.; Julian, E. C.; Kroner, R. C.; Journal-American Water Works Association., 1966, 58(10), 1363-1368.

9. McDowell, R. W.; Nash, D. M.; Robertson, F.; Journal of Environmental Quality., 2007, 36(5), 1281-1288.

10. Sharpley, A.; Wang, X.; Journal of Environmental Sciences (China)., 2014, 26(9), 1770-1782.

11. Mihajlovic, R. P.; Kaljevic, V. M.; Vukašinovic, M. P.; Mihajlovic, L. V.; Pantic, I. D.; Water SA., 2007, 33(4), 513-517.

12. Jarvie, H. P.; Withers, P. J. A.; Neal, C.; Hydrology and Earth System Sciences., 2002, 6(1), 113-132.

13. Christian G. D; Feldman J. F.; Analytica Chimica Acta., 1968, 40, 173-179.

14. Bøtker, H. E.; Kimose, H. H.; Helligsø, P.; Nielsen, T. T.; Journal of Molecular and Cellular Cardiology., 1994, 26(1), 41-48.

15. Fiske, C. H.; Subbarow, Y; Journal of Biological Chemistry., 1925, 66, 375-400.

16. Williams, K. E.; Haswell, S. J.; Barclay, D. A.; Preston, G.; The Analyst., 1993, 118(3), 245-248.

17. uinlan, Kenneth P; Desesa Michael, A.; Analytical Chemistry., 1951, 2, 1626-1629.

18. Shyla, B.; Mahadevaiah; Nagendrappa, G.; Spectrochimica Acta Part A: Molecular and Biomolecular Spectroscopy., 2011, 78(1), 497-502.

19. Mahadevaiah, Kumar, M. S. Y.; Galil, M. S. A.; Suresha, M. S.; Sathish, M. A.; Nagendrappa, G.; E-Journal of Chemistry., 2007, 4(4), 467-473.

20. Crouch, S. R.; Malmstadt, H. V.; Analytical Chemistry., 1967, 39(10), 1084-1089.

21. Dickman, S. R.; Bray, R. H.; Industrial and Engineering Chemistry Analytical Edition., 1940, 12(11), 665-668.

22. Yatirajam, V.; Dhamija, S.; Talanta., 1977, 24(8), 497-501.
23. Towns, T. G.; Analytical Chemistry., 1986, 58(1), 223-229.

24. Woods, J. T.; Mellon, M. G.; Industrial and Engineering Chemistry - Analytical Edition., 1941, 13(11), 760-764.

25. Chaube, M. A.; Gupta, V. K.; Analyst., 1983, 108, 1141- 1144.

26. Müller, A.; Das, S. K.; Krickemeyer, E.; Kuhlmann, C.; Inorganic Syntheses., 2004, 34, 191-200.

27. Ganesh, S.; Khan, F.; Ahmed, M. K.; Velavendan, P.; Pandey, N. K.; Kamachi Mudali, U.; Water Science and Technology., 2012, 66(12), 2653-2658.

28. Nagul, E. A.; McKelvie, I. D.; Worsfold, P.; Kolev, S. D.; Analytica Chimica Acta., 2015, 890, 60-82.

29. Patel, Munjal; Patel, A, Dhagash; Gajra, B.; Journal of Analytical \& Bioanalytical Techniques., 2015, 1(2), 41-50.

30. Rajendraprasad, N.; Basavaiah, K.; Vinay, K. B.; Ecletica Quimica., 2010, 35(1), 55-66.

31. Pradhan, S.; Pokhrel, M. R.; Scientific World., 2013, 11(11), 58-62.

32. Johnson, D. L.; Pilson, M. E. Q.; Analytica Chimica Acta., 1972, 58(2), 289-299.

33. Cavaleiro, A. M. V. S. V.; Gil, V. M. S.; Pedrosa de Jesus, J. D.; Gillard, R. D.; Williams, P. A.; Transition Metal Chemistry., 1984, 9(2), 62-67.

34. Zatar, N. A.; Abu-Eid, M. A.; Eid, A. F.; Talanta., 1999, 50(4), 819-826.

35. Halmi, M. I. E.; Zuhainis, S. W.; Yusof, M. T.; Shaharuddin, N. A.; Helmi, W.; Shukor, Y.; Ahmad, S. A.; BioMed Research International., 2013, 2013,1-8.

36. Othman, A. R.; Bakar, N. A.; Halmi, M. I. E.; Johari, W. L. W.; Ahmad, S. A.; Jirangon, H.; Shukor, M.Y.; BioMed Research International., 2013, 2013, 1-9.

37. Smil, V.; Annual Review of Energy and the Environment., 2000, 25(1), 53-88. 